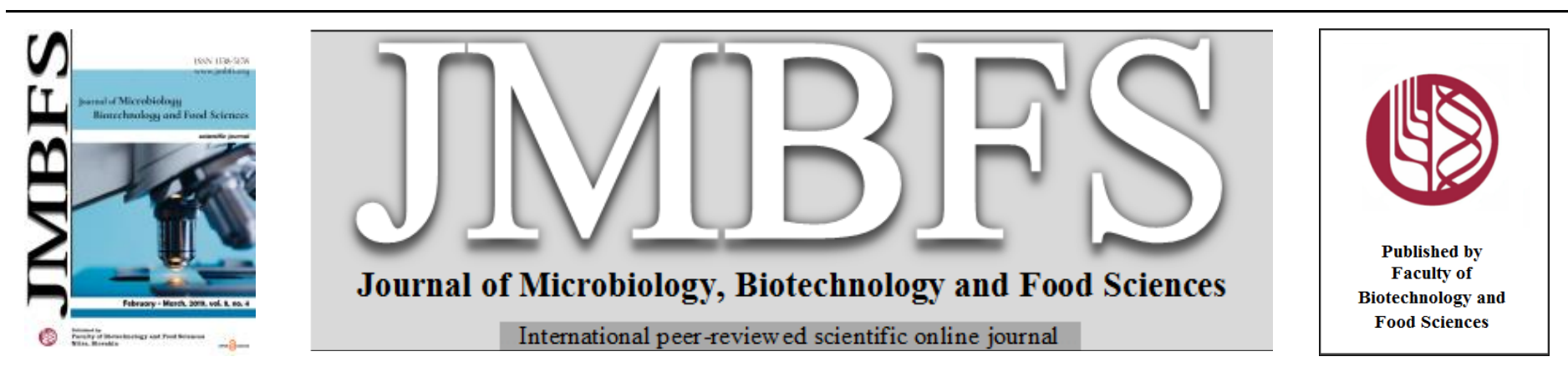

\title{
THE IN VITRO EFFECT OF THE ORIGANUM VULGARE EXTRACT ON SEMEN
}

\author{
Michal Ďuračka*l, Lucia Galovičovál, Marek Slávik², Július Árvay², Eva Tvrdál \\ Address(es): MSc. Michal Ďuračka, \\ ${ }^{1}$ Slovak University of Agriculture in Nitra, Faculty of Biotechnology and Food Sciences, Department of Animal Physiology, Tr. A. Hlinku 2, 94976 Nitra, Slovakia \\ ${ }^{2}$ Slovak University of Agriculture in Nitra, Faculty of Biotechnology and Food Sciences, Department of Chemistry, Tr. A. Hlinku 2, 94976 Nitra, Slovakia
}

*Corresponding author: michaelduracka@gmail.com

doi: 10.15414/jmbfs.2019.8.4.1089-1092

ARTICLE INFO

Received 31. 5. 2018

Revised 31. 10. 2018

Accepted 31. 10. 2018

Published 1. 2. 2019

Regular article

OPEN $\partial_{\text {ACCESS }}$

\begin{abstract}
Origanum vulgare is a medicinal and aromatic plant that has found its use all over the world. Male reproduction involves complicated morphological and physiological processes such as spermatogenesis and gamete transport into the male genital organs. The aim of this study is focused on the in vitro effect of the Origamium vulgaris on the motility, vitality and evaluation of the formation of free radicals. The heterospermic rabbit samples were diluted with culture medium supplemented with the extract of Origamium vulgaris at concentrations of $37.5 ; 75 ; 150$ and $300 \mu \mathrm{g} / \mathrm{mL}$ evaluated at time intervals of 0,2 and $8 \mathrm{~h}$. Selected chemical compounds were determined through HPLC-DAD method. From the analysed phenolic acids, rosmarinic acid was the predominant component, from flavonoids it was Cynarosid. Sperm motility was analysed using CASA (Computer-aided Sperm Analysis). The viability was analysed by the MTT (Mitochondrial Toxicity Test) test. The determination of ROS (Reactive Oxygen Species) quantity was observed through luminol method. The results showed significant decreases of motility and viability at concentrations of 300 and $150 \mu \mathrm{g} / \mathrm{mL}$ in various time periods and the ROS quantity was without any significant differences during all the experiment. We conclude that chemical composition of the Origanum extract may damage structure and function of spermatozoa. Based on this findings, we did not suggest the Origanum extract as a supplement in spermatozoa medium.
\end{abstract}

Keywords: spermatozoa, Origanum vulgare, extract, oxidative stress, mitochondrial activity, motility

\section{INTRODUCTION}

The use of medicinal plants in the treatment of diseases and dysfunctions extends to a few thousands of years back and greatly ccontributed to the development of pharmaceutical products. About $25 \%$ of modern medicines come from plants. In addition, up to $60 \%$ of the world's population is using herbal active ingredients for medical purposes (The Royal Society, 1999). The World Health Organization encourages use medicinal plants and calls on scientists to define the rational use of medicinal plant products as a source of new drugs (WHO, 2002). Several extracts of these plants are currently being used on treatment of male infertility aspects, such as: absence of libido, sexual asthenia, erectile, ejaculation and relaxation dysfunction and sperm abnormality (Kandeel, 2001). Many plants traditionallly used in the treatment of male infertility has stimulatory effects on testosterone production. The mixture of Hibiscus macranthus and Basella alba extracts stimulated testosterone production in adult males, therefore, these extracts were used to treat sexual asthenia (Moundipa, 1999). The Lepidium meyenii extract activated the beginning and progression of spermatogenesis in healthy rats. Concomitant administration with lead acetate reduced the harmful effect on sperm production caused by chemical (Rubio, 2006). Pomegranate juice (Punica granatum), which was administered to healthy rats, increased sperm concentration in the mandible, sperm motility, spermatogenic cell density, increased the diameter of the seminal vesicles and the germ cell thickness (Lin, 2007).

Leaves of Origanum are part of not only traditionally, but also official medicine Silica must contain at least $60 \%$ of carvacrol and thymol. The drug is sorted into a pharmaceutical groups of phytopharmaceuticals, in particular expectorants and choleretics. The buffering effects are used at nervousness, headaches or migraines, when the overall relaxation is induced and improves mood (Blumenthal, 1998). Moreover, side effects were not observed even for long-term administration. However, pregnant women should preventively avoid, as it can stimulate contractions of the uterus and induce premature birth or miscarriage (Baričevič, 2002). Several studies were executed to prove radical-scavenging properties the origanum extract, especially 4-(3,4Dihydroxybenzoyloxymethyl)phenyl-O- $\beta$-d-glucopyranoside isolated from Origanum vulgare, proved antioxidant and cytoprotective effects in various cell types (Sheibani et al., 2010; Liang et al., 2012; Daghigh Kia et al., 2016).
Based on these findings, which are proving wide-spectrum benefitial effects on biological system, we decided to determine phenolic acids and flavonoids in Origanum vulgare plant extract. Second part of our experiment was to evaluate in vitro effect of the extract on rabbit spermatozoa. The samples were subjected to basic semen analysis - sperm motility, subsequently vitality of spermatozoa was determined through mitochondrial activity and quantity of reactive oxygen species was analysed.

\section{MATERIAL AND METHODS}

\section{Plant material collection and processing}

The Origanum leaves were harvested at the Botanical Garden of the Slovak University of Agriculture in Nitra, Slovakia at the end of July 2016. Leaves were dried, crushed, weighed and soaked in ethanol $(96 \%$, Centralchem, Bratislava, Slovakia) during two weeks at room temperature in the dark in order to prevent the degradation of active biomolecules. To remove any residual ethanol were the ethanolic extracts subjected to evaporation under reduced pressure at $40{ }^{\circ} \mathrm{C}$ (Stuart RE300DB rotary evaporator, Bibby Scientific Limited, UK, and vacuum pump KNF N838.1.2KT.45.18, KNF, Germany). Crude extracts were dissolved in DMSO (Dimethyl sulfoxide; Sigma-Aldrich, St. Louis, USA) and adjusted to $100 \mathrm{mg} / \mathrm{mL}$ as stock solution. For the composition analysis, the leaves were freeze dried, milled and dissolved in $10 \mathrm{~mL} 80 \%$ aqueous methanol (HPLC grade; Sigma-Aldrich) to $1 \mathrm{~g}$ of each sample. The mixtures were shaken on a horizontal shaker $(250 \mathrm{rpm})$ at room temperature for $8 \mathrm{~h}$. The samples were then filtered through filter paper ( $84 \mathrm{~g} / \mathrm{m}^{2}$; Munktell, Germany) and kept at $5{ }^{\circ} \mathrm{C}$ for further analysis.

\section{HPLC-DAD analysis}

Standards, methanol (HPLC grade), acetonitrile (gradient HPLC grade) and phosphoric acid (ACS grade) were purchased from Sigma-Aldrich. Double deionized water $(\mathrm{ddH} 2 \mathrm{O})$ was treated $(0.054 \mathrm{mS} / \mathrm{cm} 1)$ in a Simplicity 185 purification system (Millipore SAS, Molsheim, France).

Standard solutions were prepared by dissolving $0.5 \mathrm{mg}$ each of them with methanol in $10 \mathrm{~mL}$. Following homogenisation the lyophilized samples $(2 \mathrm{~g})$ 
were extracted with $20 \mathrm{~mL}$ of $80 \%$ methanol at laboratory temperature for $8 \mathrm{~h}$ by horizontal shaker (Unimax 2010; Heidolph Instrument GmbH, Germany). The extract was filtered through Munktell No 390 paper (Munktell \& Filtrac, Germany) and stored in closed $20 \mathrm{~mL}$ vial tubes. Prior to injection the standard solutions and extracts were filtered through the Q-Max syringe filter $(0.22 \mathrm{~mm}, 25 \mathrm{~mm}$; Frisenette ApS Knebel, Denmark).

Chemical composition of the Origanum extract was determined using the Agilent 1260 Infinity high performance liquid chromatograph (Agilent Technologies Waldbronn, Germany) with quaternary solvent manager coupled with degasse (G1311B), sample manager (G1329B), column manager (G1316A) and DAD detector (G1315C). All HPLC analyses were performed on a Purosphere reverse phase C18 column (4 mm x $250 \mathrm{~mm}$ x $5 \mathrm{~mm}$ ) (Merck, KGaA, Darmstadt, Germany).

The mobile phase consisted of acetonitrile (gradient) (A) and $0.1 \%$ phosphoric acid in $\mathrm{ddH}_{2} \mathrm{O}(\mathrm{B})$. The gradient elution was as follows: 0-1 min isocratic elution (20\% A and $80 \%$ B), 1-5 min linear gradient elution $(25 \% \mathrm{~A}$ and $75 \% \mathrm{~B}), 5-15$ $\min (30 \% \mathrm{~A}$ and $70 \% \mathrm{~B})$ and $20-25 \mathrm{~min}(40 \% \mathrm{~A}$ and $60 \% \mathrm{~B})$. The initial flow rate was $1 \mathrm{~mL} / \mathrm{min} 1$ and the injection volume was $10 \mathrm{~mL}$. Column oven temperature was set up to $30{ }^{\circ} \mathrm{C}$ and the samples were kept at $4{ }^{\circ} \mathrm{C}$ in the sample manager. The data were collected and processed using the Agilent OpenLab ChemStation software for LC 3D Systems (Lukšič et al., 2016).

\section{Semen sample collection and processing}

Ejaculates $(n=20)$ were obtained from 10 adult healthy New Zealand rabbits (Research Institute For Animal Production, Nitra, Slovak Republic) using an artificial vagina. The semen samples were transported to the laboratory in thermos due to keeping the constant temperature. To get enough of the sample volume for the control and experimental groups, were selected semen samples mixed to create heterospermic sample with a volume of $4 \mathrm{~mL}$. The selection of the semen samples was based on the sperm quality parametres (minimum $70 \%$ motility and sperm concentration of $1 \times 10^{9} \mathrm{sperm} / \mathrm{mL}$ ), subsequently these samples were used for the experiments. Institutional and national guidelines for the care and use of animals were followed, and all experimental procedures were approved by the State Veterinary and Food Institute of Slovak Republic (no. 3398/11-221/3) and Ethics Committee.

Each sample was diluted in PBS (Dulbecco's Phosphate Buffer Saline withou calcium chloride and magnesium chloride; Sigma-Aldrich) containing various concentrations of the Origanum extract $(300 ; 150 ; 75 ; 37.5 \mu \mathrm{g} / \mathrm{mL})$ using a dilution ratio of $1: 40$. The samples were cultured at laboratory temperature (22 $25^{\circ} \mathrm{C}$ ). After culture periods of 0,2 and $8 \mathrm{~h}$, spermatozoa motility, mitochondrial activity and reactive oxygen species (ROS) production were assessed in each group.

\section{Spermatozoa motility analysis}

Spermatozoa motion were assessed using the computer-aided sperm analysis (CASA; Version 14.0 TOX IVOS II.; Hamilton-Thorne Biosciences, Beverly, MA, USA). The system was set up as follows: frame rate - $60 \mathrm{~Hz}$; minimum contrast - 20; static head size - 0.25-5.00; static head intensity - 0.40-2.00; static elongation - 20-100; default cell size - 4 pixels; default cell intensity - 40. Ten $\mu \mathrm{L}$ of each sample were placed into the Makler counting chamber (depth $10 \mu \mathrm{m}, 37$ ${ }^{\circ} \mathrm{C}$; Sefi Medical Instruments, Haifa, Israel) and immediately assessed for spermatozoa motility (MOT; percentage of motile spermatozoa; motility $>5 \mathrm{~m} / \mathrm{s}$, $\%)$. Ten microscopic fields were subjected to each analysis to include at least 300 cells.

\section{Mitochondrial activity (MTT test)}

Spermatozoa mitochondrial activity was assessed using the colorimetric metabolic activity (MTT) test, which is based on the conversion of a yellow tetrazolium salt (3-(4,5-dimetylthiazol-2-yl)-2,5-diphenyltetrazolium bromide MTT) to blue formazan particles by mitochondrial succinate dehydrogenase of intact mitochondria within living cells. The tetrazolium salt (Sigma-Aldrich) was dissolved in PBS (Dulbecco's Phosphate Buffer Saline without calcium chloride and magnesium chloride; Sigma-Aldrich) at $5 \mathrm{mg} / \mathrm{mL}$. Twenty $\mu \mathrm{L}$ of the tetrazolium solution was added to each sample. After a $2 \mathrm{~h}$ incubation (shaker, 37 ${ }^{\circ} \mathrm{C}, 95 \%$ air atmosphere, $\left.5 \% \mathrm{CO} 2\right)$, the formazan crystals were dissolved in $80 \mu \mathrm{L}$ of acidified $(0.08 \mathrm{~mol} / \mathrm{L} \mathrm{HCl}$; Centralchem) isopropanol (Centralchem). Optical density was determined at a wavelength of $570 \mathrm{~nm}$ against $620 \mathrm{~nm}$ as reference using a Multiskan FC microplate photometer (Thermo Fisher Scientific Inc., Waltham, MA, USA). Data are expressed as percentage of the control set to $100 \%$.

\section{Reactive oxygen species (ROS) generation}

ROS production in each group was analysed by the chemiluminescence assay using luminol (5-amino-2,3-dihydro-1,4-phthalazinedione; Sigma-Aldrich) as the probe (Kashou et al., 2013). The blank consisted of $400 \mu \mathrm{L}$ of PBS. Negative control contained $400 \mu \mathrm{L}$ of PBS, luminol $(10 \mu \mathrm{L}, 5 \mathrm{mM})$ and positive control contained extra $25 \mu \mathrm{L}$ of hydrogen peroxide (30\%; $8.8 \mathrm{M}$; Sigma-Aldrich). The tested control and experimental samples consisted of $400 \mu \mathrm{L}$ of sample and luminol. Chemiluminescence was measured on 48-well plates in 15 cycles of 1 min using the Glomax Multi ${ }^{+}$Combined Spectro-Fluoro Luminometer (Promega Corporation, Madison, WI, USA). The results are exppressed as relative light units (RLU)/s/ $10^{6}$ spermatozoa cells

\section{Statistical analysis}

Statistical analysis was carried out using the GraphPad Prism program (version 3.02 for Windows; GraphPad Software, La Jolla, CA, USA http://www.graphpad.com). Descriptive statistical characteristics (mean, standard error) were evaluated at first. One-way ANOVA was used for specific statistica evaluations. Dunnett's test was applied as a follow-up test to ANOVA, based on a comparison of every mean to a control mean, and computing a confidence interval for the difference between the two means. The level of significance was set at $* * * *_{-} \mathrm{P}<0.001, * *_{-} \mathrm{P}<0.01, *{ }_{-} \mathrm{P}<0.05$

\section{RESULTS AND DISCUSSION}

The aim of present study was to investigate samples of rabbit ejaculates exposed to different concentrations $(300,150,75$ and $37.5 \mu \mathrm{g} / \mathrm{mL})$ of the Origanum extract in different time periods $(0,2$ and $8 \mathrm{~h})$. From the results of our research, it is clear that the extract has no effect on motility or mitochondrial activity at low concentrations. Negative effects of higher concentrations were evident.

High performance liquid chromatography (HPLC) was used for the identification and quantification of major chemical compounds present in the Origanum extract. The quantitative determination was performed by the external standard method and the concentrations of the identified compounds are showed in Table 1. The main compound detected in the extract was Cynarosid $(259.11 \pm 8.01$ $\mathrm{mg} / \mathrm{kg}$ ). From the analyzed phenolic acids, rosmarinic acid, trans-caffeic acid, neochlorogenic acid, sinapinic acid, trans-ferulic, chlorogenic acid and trans-pcoumaric acid were quantified with the first being the most abundan $(203.42 \pm 7.55 \mathrm{mg} / \mathrm{kg})$. Six flavonoid glycosides, cynarosid, rutin, apigenin, kaempferol, vitexin and daidzein were found in the Origanum extract (Table 1).

Table 1 Major chemical compounds identified and quantified $[\mathrm{mg} / \mathrm{kg}]$ in the Origanum extract

\begin{tabular}{lc}
\hline Cynarosid & $259.11 \pm 8.01$ \\
Rutin & $30.02 \pm 1.99$ \\
Apigenin & $4.72 \pm 0.66$ \\
Kaempferol & $15.67 \pm 2.33$ \\
Vitexin & $31.99 \pm 3.55$ \\
Daidzein & $71.70 \pm 5.33$ \\
Chlorogenic acid & $6.85 \pm 0.69$ \\
Neochlorogenic acid & $46.82 \pm 1.88$ \\
trans-p-Coumaric acid & $5.50 \pm 0.99$ \\
Trans-Caffeic acid & $51.34 \pm 3.79$ \\
Trans-Ferulic acid & $7.30 \pm 1.05$ \\
Sinapinic acid & $14.28 \pm 2.00$ \\
Rosmarinic acid & $203.42 \pm 7.55$ \\
\hline
\end{tabular}

$($ Mean \pm SEM; $n=3)$

The rabbit sperm motility analysis was performed using the CASA system. At the beginning of the experiment, the highest concentration of the Origanum vulgare extract $(300 \mu \mathrm{g} / \mathrm{mL})$ had an immediate negative effect on sperm motion characteristics as well as $150 \mu \mathrm{g} / \mathrm{mL}$ had a negative effect on sperm motility, but no statistically significant difference. Low concentrations of extract (75 and 37.5 $\mu \mathrm{g} / \mathrm{mL}$ ) did not affect on sperm motility with any significant difference. After $2 \mathrm{~h}$, there was established descending trend of sperm motility with increasing concentration of the Origanum extract. High concentrations strongly decreased motility, while low concentrations neither supported nor harmed sperm motility. Also after an eight-hour Origanum exposure to spermatozoa, were observed significant decreases in samples treated with high concentrations. 
Motility Oh
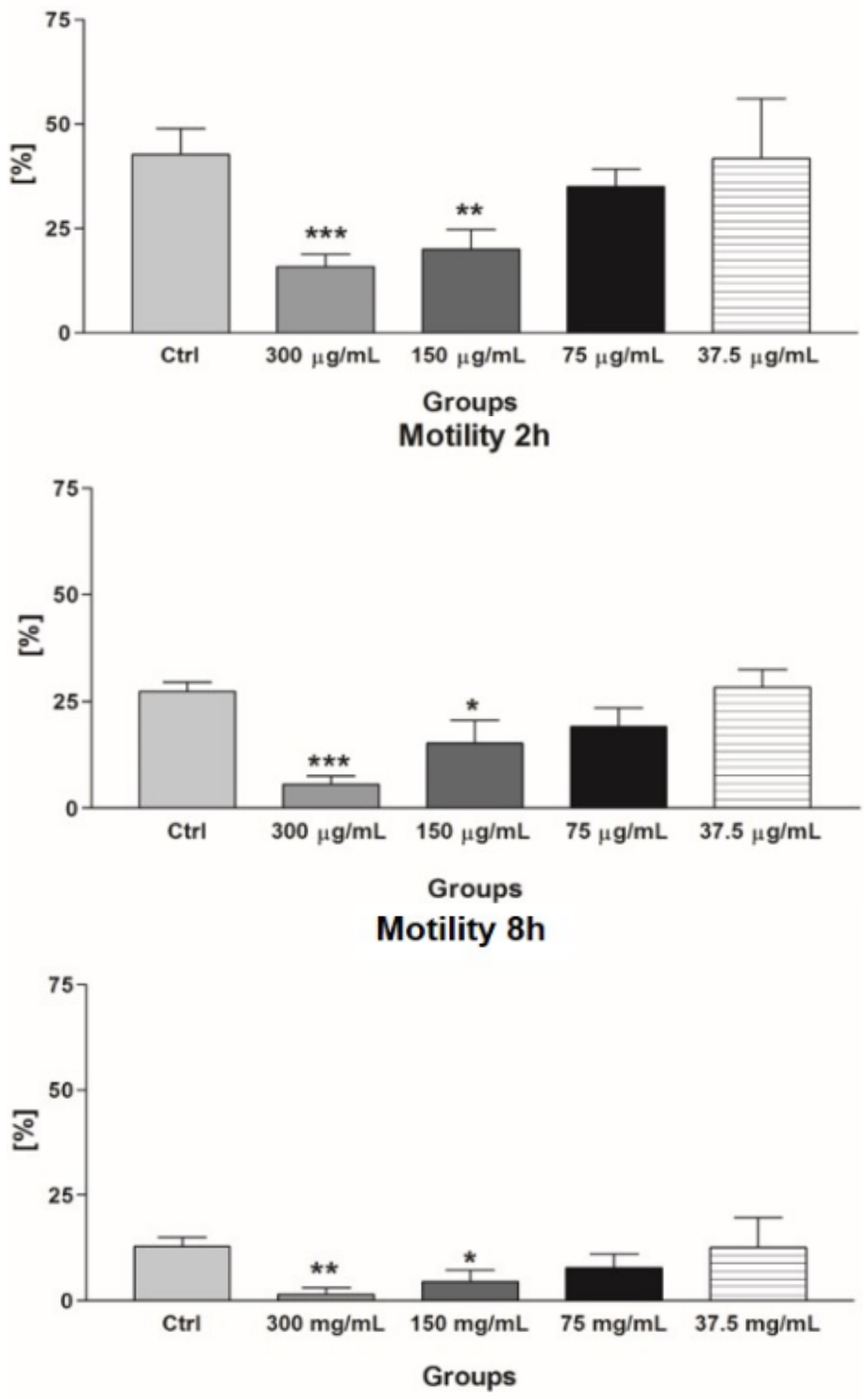

Figure 1 Development of sperm motility during $8 \mathrm{~h}$ cultivation with the various concentrations of the Origanum extract, Legend: $* \mathrm{P}<0.05$; ** $\mathrm{P}<0.01$; *** $\mathrm{P}<$ 0.001

Mitochondrial activity is directly linked to sperm motility, as mitochondria are the source of energy for movement of the sperm. Therefore, we decided to analyze effect of the Origanum extract on mitochondria viability. Initially, no significant differences were observed. After $2 \mathrm{~h}$, was observed a slight increase in the group treated with $37.5 \mu \mathrm{g} / \mathrm{mL}$, when compared to Control. After $8 \mathrm{~h}$ of incubation with the Origanum extract, the high concentrations significantly decreased mitochondrial viability. The stimulating effect of the Origanum extract did not manifest significantly in either one from time intervals. We cannot confirm positive effects of the Origanum extract on sperm vitality. Conversly, higher concentrations demonstrated an inhibitory effect on sperm viability.

\section{Mitochondrial activity $\mathbf{0 ~} \mathrm{h}$}

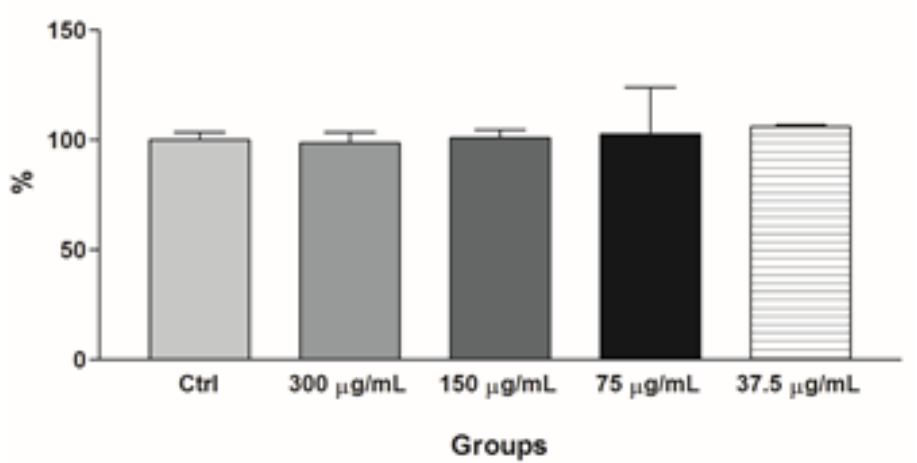

Mitochondrial activity $2 \mathrm{~h}$

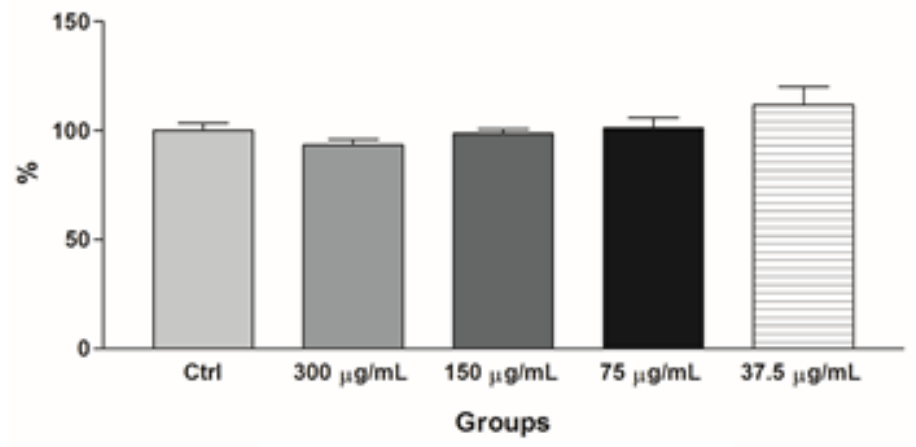

Mitochondrial activity $8 \mathrm{~h}$

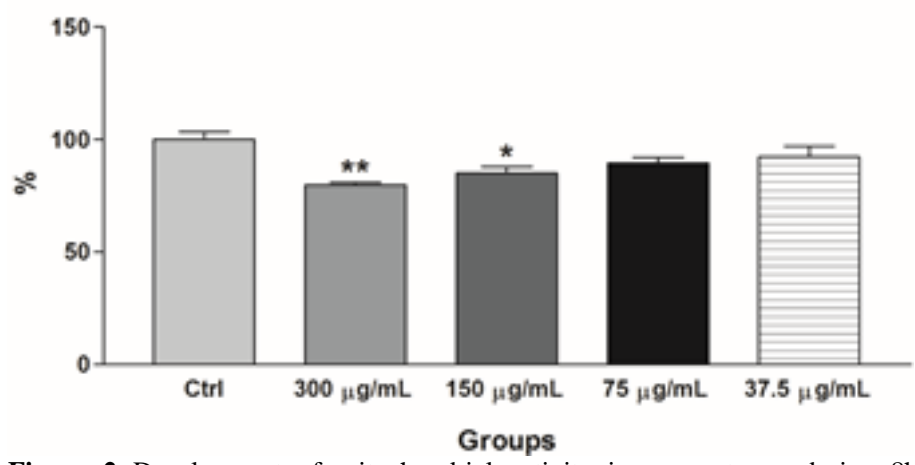

Figure 2 Development of mitochondrial activity in spermatozoa during $8 \mathrm{~h}$ cultivation with the various concentrations of the Origanum extract, Legend: * $\mathrm{P}<$ $0.05 ; * * \mathrm{P}<0.01$

ROS quantification was performed due to high production may affect the plasma membrane of the sperm and then on functional integrity of the cell. Increased level of ROS leads to reduced motility and vitality. At $0 \mathrm{~h}$, we experienced a small increase in ROS production at higher concentrations (300 and $150 \mu \mathrm{g} / \mathrm{mL}$ ). The difference was not statistically significant. At concentrations of 75 and 37.5 $\mu \mathrm{g} / \mathrm{mL}$, there was almost no effect. In the next stage of the experiment, at higher concentrations, there was also a slight increase in the ROS production without any significance. At lower concentrations, the increase was only very weak and as well as at higher concentrations, without any significance, when compared to Control. Surprisingly, even after $8 \mathrm{~h}$ of extract exposure, there was no significant difference between Control and experimental groups. Therefore, we deduced that Origanum extract did not offer nor a stimulatory neither inhibitory effect with respect to oxidative stress.

Sá et al. (2006) in their study analysed the effect of short-term administration of Origanum officinalis water extract on vital organs, organs of the reproductive system and on production of sperm of male Wistar rats. Adult males (90 days) weighing approximately $250 \mathrm{~g}$, were randomly divided into three experimenta groups. Then they were subjected to a 5-week reproductive toxicity test. Two experimental groups were administered once daily with $1 \mathrm{~mL}$ of the water extract with $291.2 \mathrm{mg} / \mathrm{kg}$, while the third group was treate with a double dose $(582.4$ $\mathrm{mg} / \mathrm{kg}$ ). The control group recieved $1 \mathrm{~mL}$ of distilled water. Administration of a double dose resulted in a significant decrease in the weight of the seed vesicles, while the weight of the other analyzed organs was not significantly altered. The change in the weight of the reproductive organs is under hormonal control and therefore its change may indicate an impairment of reproductive endocrine functions. Any pituitary damage may interfere with the male reproductive system, which affects the production of sex steroid hormones and male gametes. Apart from the effect of the extract on the endocrine system, the adverse effect of the extract is also on the concentration of spermatozoa, which is a potential marker of toxicity. Preliminary assessment of the poslible reproductive toxicity of the Origanum extract administered to adult Wistar rats has shown an adverse effects on seminal vesicles, but indiccates that the adverse effects on the testes, the dendritic and the prostate are not toxic. 


\section{ROS production $0 \mathrm{~h}$}
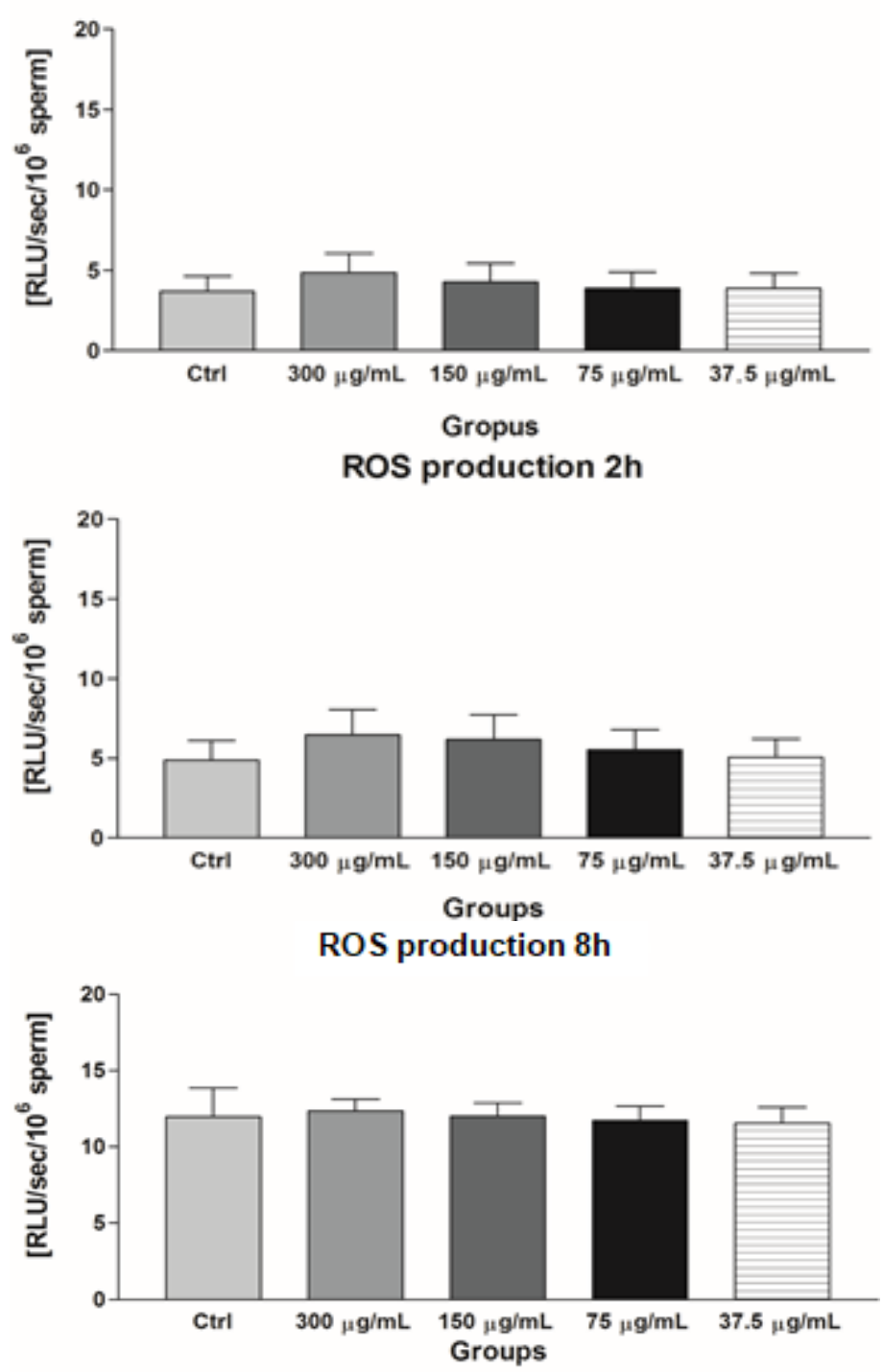

Figure 3 Development of ROS production in spermatozoa during $8 \mathrm{~h}$ cultivation with the various concentrations of the Origanum extract

Balubaid (2010) studied protective effect of Origanum majorana against the toxicity of cadmium chloride on testicular tissue of 60 -day-old white rats. The cadmium treated group exhibited an imbalance in the structure and physiology of the testes. Spermatogenesis and spermiogenesis also resulted in degradation of spermatocytes, reduction of their concentration, deformation of their structure and low testosterone levels. The simultaneous administration of cadmiun and the Origanum extract reduced histopathological changes in tissue structure and balanced levels of testosterone. The author believes that the use of Origanum Majorana as a protective agent is safe and can icrease fertility in males.

Chen et al. (2007) investigated the effect of the Origanum vulgare essential oil on the male reproductive organs of rats. The results of this studdy showed that essential oil reduced weight of the testes and caused damage to their tissues. At the highest dose there were metabolic disorders and decreased testosterone levels. The effect of essential oil on the testicles is also responsible for low sperm concentration and production of abnormal gametes.

\section{CONCLUSION}

In our study we focused on determination of chemical composition of the Origanum vulgare extract. The second part of this study was to examine the in vitro effect of the Origanum extract on male reproductive markers: spermatozoa motility, mitochondrial activity, quantification of ROS as a marker of oxidative stress, which is one of the essential threats influencing on the success of fertility. The results of our study showed that the Origanum extract had no significant effect on motility and mitochondrial activity at low concentrations (75 and 37.5 $\mu \mathrm{g} / \mathrm{mL}$ ). Negative effects of higher concentrations (300 and $150 \mu \mathrm{g} / \mathrm{mL}$ ) are evident and have been demonstrated after $2 \mathrm{~h}$ of exposure and persisted also after 8h. In the case of mitochondrial activity, the negative effect of higher concentrations was apparent after an $8 \mathrm{~h}$ exposure. Unexpectedly, regarding the production of ROS neither one of the four concentrations did not show any significant effects in every time periods. We conclude that the Origanum vulgare extract contains cytotoxic substances that act inhibitory at high concentrations By inhibiting mitochondrial activity and sperm motility, their viability decreases, resulting in irreversible structural and functional damage to male gametes. At low concentrations, the extract did not have any affect on male reproductive cells Although, we did not suggest the Origanum extract as a potential storage medium, maybe more complex sperm analyses and in vivo experiments could explain more thoroughly the effect of the Origanum vulgare extract on male reproductive system.

Acknowledgments: This study was supported by the European Community Project no. 26220220180: Building Research Centre „AgroBioTech“, by the Scientific Grant Agency of the Ministry of Education of the Slovak Republic and of the Slovak Academy of Sciences VEGA no. 1/0039/16 and by the Slovak Research and Development Agency Project no. APVV-15-0544.

\section{REFERENCES}

BALUBAID, S.O.A.B. 2010. Protective effect of Marjoram plant against the toxicity of cadmium chloride in testes of albino rat. Biosciences, Biotechnology Research Asia, 7(2), 667-674.

BARICEVIC, D., BARTOL, T. 2002. The biological/pharmacological activity of the Origanum Genus, London : Oregano: The genera Origanum and Lippia, 177 214. ISBN 97-80-415-369-43-5

BLUMENTHAL, M. 1998. The Complete German Commission E Monographs Therapeutic Guide to Herbal Medicines. Austin : The American Botanical Council, 685 p. ISBN 09-65-555-50-X.

DAGHIGH KIA, H., FARHADI, R., HOSSEINKHANI, A., ASHRAFI, I. 2015.

The effect of Origanum vulgare extract on kinetics and viability of cryopreserved Holstein semen. 66th Annual Meeting of the European Federation of Animal Science, Warsaw, 535

CHEN, H., MIDZAK, A., LUO, L., ZIRKIN, B.R. 2007. Aging and decline of androgen production. Leydig cell in health and disease. Contemporary Endocrinology, 2, 117-131. https://doi.org/10.1007/978-1-59745-453-7 7 KANDEEL, R.F., KOUSSA, T.K.V., SWERDLOFF, S.R. 2001. Male sexua function and its disorders: physiology, pathophysiology, clinical investigation and treatment. Endocrine Reviews, 22, 342-388 https://doi.org/10.1210/edrv.22.3.0430

KASHOU, A. H., SHARMA, R., AGARWAL, A. 2013. Assessment of oxidative stress in sperm and semen. Spermatogenesis, 927, 351-361. https://doi.org/10.1007/978-1-62703-038-0 30

LIANG, C.H., CHAN, L.P., DING, H.Y., So, E.C., LIN, R.J., WANG, H.M., CHENG Y.G., CHOU, T.H. 2012. Free radical scavenging activity of 4-(3, 4 dihydroxybenzoyloxymethyl) phenyl-O- $\beta$-D-glucopyranoside from Origanum vulgare and its protection against oxidative damage. Journal of agricultural and food chemistry, 60(31), 7690-7696. https://doi.org/10.1021/jf302329m

LIN, WH. - TSAI, MT. - CHEN, YS. et al. 2007. Improvement of sperm production in subfertile boars by Cordyceps militaris (Supplement). In: The American Journal of Chinese Medicine, 35(4), 631-641. https://doi.org/10.1142/S0192415X07005120

LUKŠIČ, L., ÁRVAY, J., VOLLMANNOVÁ, A., TÓTH, T., ŠKRABANJA, V., TRČEK, J., GERM, M., KREFT, I. 2016. Hydrothermal treatment of Tartary buckwheat grain hinders the transformation of rutin to quercetin. Journal of Cereal Science 16(72), 131-134. https://doi.org/10.1016/j.jcs.2016.10.009 MOUNDIPA, F.P., KAMTCHOUING, P., KOUETA, N., TANTCHOU, J., FOYANG, N.P.R, MBIAPO, F.T. 1999. Effects of aqueous extracts of Hibiscus macranthus and Basella alba in mature rat testis function. Journal of Ethnopharmacology, 65(2), 133-139. https://doi.org/10.1016/S03788741(98)00207-4

RUBIO, J., RIQUEROS, I.M., GASCO, M., YUCRA, S., MIRANDA, S., GONZALES, G.F. 2006. Lepidium meyenii (Maca) reversed the lead acetate induced - Damage on reproductive function in male rats. Food and Chemical Toxicology, 44(7), 1114-1122. https://doi.org/10.1016/i.fct.2006.01.007

SÁ, R.C.S., LEITE, M.N., OLIVEIRA, L.E.G., TOLEDO, M.M., GREGGIO T.C., GUERRA, M.O. 2006. Preliminary assessment of Origanum officinalis toxicity on male Wistar rats' organs and reproductive system. Revista Brasileira de Farmacognosia, 16(3), 324-332. $\quad$ http://dx.doi.org/10.1590/S0102695X2006000300008

SHEIBANI, V., AFARINESH, M., HAJIALIZDEH, Z., ABBASNEJAD, M., HAGHPANAH,T., ARABNEZHAD, R., SEPEHRI, G. 2011. Evaluation of Origanum Vulgare L. ssp. viridis leaves extract effect on discrimination learning and ltp induction in the cal region of the rat hippocampus. Iranian Journal of $\begin{array}{llll}\text { Basic Medical } & \text { Sciences, } & 14(1), & 177-184\end{array}$ https://doi.org/10.22038/ijbms.2011.4984

The Royal Society. 1999. Complementary and alternative medicine. Response to the House of Lords inquiry into complementary and alternative medicine. Ref: 18/99: 1-7.

WHO. 2002. WHO traditional medicine strategy 2002-2005. Edited by Quick JD, Sawyer J, Thorpe P, Whitney D, Zhang X. World Health Organization, Geneva. 